\title{
Assessment of the economic efficiency of the innovative development of industrial enterprises
}

\author{
Natalia Shchepkina ${ }^{1, *}$ \\ ${ }^{1}$ Moscow State University of Civil Engineering, 129337, Yaroslavskoe shosse, 26, Moscow, Russia
}

\begin{abstract}
The savings received from the implementation of innovative measures are usually associated with the results of other measures regarding the expansion of production capabilities. In this regard, it is advisable to consider the impact of innovative development of an enterprise on the efficiency of its activities in the framework of studying the economic efficiency of scientific and technological progress and its impact on reducing costs and not using effective innovations in production. The canonical correlation method is used, which allows one to simultaneously analyze the systems of indicators of production efficiency and the factors that define it. To analyze and assess the efficiency of the innovative development of an enterprise, an optimal combination of factors for its increase is proposed, based on the fact that many factors affecting the efficiency of economic activity, together with the complexity of their relationships, have optimal ranges of actions.
\end{abstract}

\section{Introduction}

The experience of developed countries shows that with the growth of scientific and technological activities in the field of production, the volume of work associated with the interaction of various economic entities increases. Such entities are other enterprises, research and design institutes, and higher educational institutions.

The specifics of production affect the ways to solve the problems of innovation and the science-production symbiosis. This is caused by the fact that its result is a single, complex, and often unique project, which is implemented by order of the investor for a sufficiently large period of time. All this does not allow the enterprise to carry out innovative activities at the level of finished commodity products, offering it on the market.

However, introducing new materials, new designs and technologies into production, one can get a qualitatively new production service in the form of the possibility of creating a project that is in high demand among potential customers due to its originality and uniqueness.

A feature of the modern stage of development of innovative activity is the formation of powerful scientific and technological complexes at large enterprises, which combine a single

\footnotetext{
* Corresponding author: natasha.chepkina@mail.ru
} 
process of research and production. This implies the existence of close ties at all stages of the science-production cycle. The creation of an integrated scientific-production and marketing complex is objectively logical and is determined by scientific and technological progress and market economic conditions.

One of the important and difficult tasks that arise in this case before economic science is the determination of the economic efficiency of the innovative way of enterprise development in the market conditions. The savings received from the implementation of innovative measures are usually associated with the results of other measures regarding the expansion of production capabilities. In this regard, it is advisable to consider the impact of innovative development of an enterprise on the efficiency of its activities in the framework of studying the economic efficiency of scientific and technological progress and its impact on reducing costs and not using effective innovations in production.

The studies of various aspects of innovation in theoretical and applied aspects are the work of many domestic scientists: L. Vodachek, Vodachkova O. [1], Yu. Yakovets [2], S. Ilyenkova, L. Gokhberg, S. Yagudin [3], L. Ogoleva [4], R. Fathutdinov [5] and others.

The most famous foreign researchers of this problem are: J. Schumpeter [6], G. TeelingSmith [7], Jan Verloop [8], Lars Frølund Max Riedel [9], C. Freeman [10], Charis Galanakis [11], Marian Garcia Martinez [12], Peter Weegels [13], Craig Leadley [14], J.J. Lambin [15], R. Tucker [16] and others.

The first most complete description of innovations was introduced into the economic science by the Austrian scientist J.A. Schumpeter in "The Theory of Economic Development". The classic theory of innovation begins with this study. According to J. Schumpeter, innovation is not just new developments, but a factor of production. The massive emergence of "new combinations", according to Schumpeter, indicates the beginning of an economic recovery.

The famous foreign scientist G. Teeling-Smith addresses the issues of trilateral relations between science, industry and the state. Jan Verloop studies the innovation process to understand the characteristics of well-managed innovation efforts. Lars Frølund Max Riedel addresses the key issues of cooperation between universities and industry, describes the success factors of cooperation between leading world companies and universities. C. Freeman pays particular attention to research processes, methodologies and indicators of progress in science and technology.

Foreign researchers pay particular attention to innovation in various industries. Thus, Charis Galanakis considers the interaction of the scientific community and industry, describes innovations and long-term $R \& D$ strategies to overcome the bottlenecks in transferring know-how between the two sectors, talks about the use of innovative solutions in the field of food science and their application in the food industry. M. Garcia Martinez studies the challenges and opportunities offered by the inclusion of "open innovation" in the food industry. Peter Weegels analyzes the key innovative challenges facing the grain industry to meet the demands and expectations of consumers.

Craig Leadley studies the driving forces of change and innovation in the food industry, as well as current and future solutions to such problems as lower energy consumption and higher food costs.

In the works of these authors, various aspects of innovation, including in industry, are covered. However, the issue of the impact of the innovative development of an enterprise on the efficiency of its activities has not been adequately studied, which has made this study relevant.

Based on this, the formation of theoretical and methodological approaches to the economic assessment of the efficiency of the innovative path of development of an industrial enterprise is of particular interest today. 


\section{Materials and Methods}

The following indicators can be used as initial information for analysis and assessment of the efficiency of the innovative path of enterprise development:

$\mathrm{y}_{1}$ - a qualitative indicator of production, reflecting the cost of work and services;

$\mathrm{y}_{2}$ - the cost of new materials, structures and technologies associated with their introduction into production;

$\mathrm{y}_{3}$ - the level of stocks of new materials and structures per ruble of the volume of work and services performed.

These indicators together reflect the level of efficiency of using the results of scientific and technological progress. As the main factors affecting the efficiency of the innovative path of development of an enterprise and characterizing the rapid growth of production on the basis of scientific and technological progress, we can use:

$\mathrm{x}_{1}$ - expenses for the development and implementation of innovations in production, as well as production development;

$\mathrm{x}_{2}-$ the volume of work and services performed in value terms; $\mathrm{PC}$;

$\mathrm{x}_{3}-$ expenses of the enterprise for the acquisition of new information technologies and

$\mathrm{x}_{4}$ - profit due to more intensive operation of equipment;

$\mathrm{x}_{5}-$ the level of provision of new materials and structures;

$\mathrm{x}_{6}$ - the cost of continuing education and retraining of personnel;

$\mathrm{x}_{7}$ - provision of material resources and funds for the development of production, science and technology;

$\mathrm{x}_{8}$ - payment level of one person-day;

$\mathrm{x}_{9}$ - increase in the wage fund by $1 \%$ of the premium for updated commodity products;

$\mathrm{x}_{10}-$ use of funds for social development, housing construction for its employees and other social facilities.

The different level and combination of production indicators complicate the assessment of the efficiency of the innovative path of enterprise development through the complexity of unequivocally establishing the relationship between the system of performance indicators and factors.

To solve this task in practice, it is advisable to use the canonical correlation method, which allows one to simultaneously analyze the system of indicators of production efficiency and the factors that determine it [17].

However, to solve the problem under consideration using the indicated method, experimental data are needed both on the values of the performance indices $y_{j}, j=1 \ldots, 3$ and on the values of the factors $x_{i}, i=1 \ldots, 10$, which are almost impossible to obtain in advance for assessing the efficiency of introducing innovations into production. Therefore, it is proposed to use the method for determining the efficiency of introducing innovations into production, which avoids the difficulty of assessment.

This method is based on expert data obtained by interviewing highly qualified economists and managers, and processing this data using the apparatus of fuzzy sets [18] and regression analysis methods [19]. Imagine the relationship between performance estimates and factors in the form of a system of algebraic equations:

$$
\left\{\begin{array}{c}
b_{1} y_{1}=a_{11} x_{1}+a_{12} x_{2}+a_{13} x_{3}+\ldots+a_{1,10} x_{10} \\
b_{2} y_{2}=a_{21} x_{1}+a_{22} x_{2}+a_{23} x_{3}+\ldots+a_{2,10} x_{10} \\
b_{3} y_{3}=a_{31} x_{1}+a_{32} x_{2}+a_{33} x_{3}+\ldots+a_{3,10} x_{10}
\end{array}\right\}
$$

In general form, this can be represented as follows: 


$$
y_{j}=\sum_{i=1}^{10} \frac{a_{j i}}{b_{j}} x_{i}, j=1, \ldots, 3
$$

We define each indicator $\mathrm{y}_{j}$ and the factor $\mathrm{x}_{i}$, which affects it using the linguistic variable of the same name [19], represented by five terms: "very small value", "small value", "average value", "large value", "very large value", where $\mathrm{y}_{11}, \mathrm{y}_{12} \ldots \mathrm{y}_{15}$ are the boundary values of the terms of the corresponding linguistic variable. Thus, we have a total of thirteen linguistic variables represented in a similar way.

Further, based on a survey of experts, we establish for all estimates $\mathrm{y}_{j}$ the values of the factors $\mathrm{x}_{i}$ that affect them in a fuzzy form (Table 1).

Table 1. The relationship between the qualitative values of the indicator $y_{j}$ and factors $x_{i}$

\begin{tabular}{|c|c|c|l|l|l|}
\hline \multirow{2}{*}{$\begin{array}{l}\text { Qualitative } \\
\text { values of } \\
\text { the factors } \\
\mathrm{x}_{i}\end{array}$} & \multicolumn{5}{|c|}{ Qualitative values of the indicator $\mathrm{y}_{j}$} \\
\cline { 2 - 6 } & $\begin{array}{l}\text { Very small } \\
\mathrm{y}_{11}\end{array}$ & Small $\mathrm{y}_{12}$ & $\begin{array}{l}\text { Average } \\
\mathrm{y}_{13}\end{array}$ & Large $\mathrm{y}_{14}$ & $\begin{array}{l}\text { Very large } \\
\mathrm{y}_{15}\end{array}$ \\
\hline $\mathrm{x}_{1}$ & Average & Large & Very large & Very large & Very large \\
\hline $\mathrm{x}_{2}$ & Small & Small & Average & Average & Large \\
\hline$\ldots$ & $\ldots$ & $\ldots$ & $\ldots$ & $\ldots$ & $\ldots$ \\
\hline $\mathrm{x}_{10}$ & Very large & Large & Average & Average & Small \\
\hline
\end{tabular}

Using the method of transition from a fuzzy presentation of data to a clear maximum membership functions according to table 1, we will make table 2 .

Table 2. The relationship between the quantitative values of the indicator $y_{j}$ and the values of the factors $\mathrm{x}_{i}$

\begin{tabular}{|c|c|c|c|c|c|}
\hline \multirow{2}{*}{$\begin{array}{c}\text { Qualitative values of } \\
\text { the factors } \mathrm{x}_{j}\end{array}$} & \multicolumn{5}{|c|}{ Qualitative values of the indicator $\mathrm{y}_{j}$} \\
\cline { 2 - 6 } & $\mathrm{y}_{11}^{*}$ & $\mathrm{y}_{12}^{*}$ & $\mathrm{y}_{13}^{*}$ & $\mathrm{y}_{14}^{*}$ & $\mathrm{y}_{15}^{*}$ \\
\hline $\mathrm{x}_{1}$ & $\mathrm{x}_{13}^{*}$ & $\mathrm{x}_{14}^{*}$ & $\mathrm{x}_{15}^{*}$ & $\mathrm{x}_{15}^{*}$ & $\mathrm{x}_{15}^{*}$ \\
\hline $\mathrm{x}_{2}$ & $\mathrm{x}_{22}^{*}$ & $\mathrm{x}_{22}^{*}$ & $\mathrm{x}_{23}^{*}$ & $\mathrm{x}_{23}^{*}$ & $\mathrm{x}_{24}^{*}$ \\
\hline & & & & & \\
\hline $\mathrm{x}_{10}$ & $\mathrm{x}_{10.5}^{*}$ & $\mathrm{x}_{10.4}^{*}$ & $\mathrm{x}_{10.3}^{*}$ & $\mathrm{x}_{10.3}^{*}$ & $\mathrm{x}_{10.2}^{*}$ \\
\hline
\end{tabular}

Considering the coefficients $a_{i j} / b_{j}$ as unknown parameters, and the data in table 2 as expert data, we determine the values of the coefficients for the given factors by the least squares method. As a result, we obtain the established functional relationship between the performance indicators of innovation and the factors that act on it.

$$
y_{j}=\sum_{i=1}^{10} a_{j i} x_{i}, j=1, \ldots, 3
$$

\section{Results}

One of the key tasks of a comprehensive analysis of the efficiency of innovative development of an enterprise is to determine the optimal combination of factors for its increase [20]. This 
is due to the fact that many factors that affect the efficiency of economic activity, together with the complexity of their relationships, have optimal ranges of action. Thus, in order to substantiate ways to increase production efficiency, it is necessary to determine the optimal values of factors and their combination.

Factors that have an optimal range of actions include, for example, the level of specialization and cooperation of production, technical transformation, expansion of production, etc. Achieving high production efficiency is associated with determining the optimal values of these factors. The most important condition for increasing the efficiency of economic activity is to find the optimal ratio of the level of increase in the wage fund and the additional volume of performed work due to outstripping production growth based on scientific and technological progress.

The solution of this problem is reduced to the construction of the Lagrange function based on the obtained linear system of equations:

$$
y_{j}=\sum_{i=1}^{10} a_{j i} x_{i}, j=1, \ldots, 3
$$

which has the following form:

$$
\Phi=\mathrm{y}_{j}+\sum_{j=2}^{3} \lambda_{j}\left(\mathrm{y}_{j}-\sum_{i=1}^{10} a_{j i} x_{i}\right)
$$

This function is taken as a quality criterion and optimized for given constraints of the form $\mathrm{x}_{i}>0$, assumed taking into account the capabilities of the factors $\mathrm{x}_{i}$, according to which they cannot have negative values, and provided that all the equations in this system, except the first one, are considered as equality type constraints.

\section{Conclusion}

In the framework of this study concerning the determination of the economic efficiency of the innovative development path of an industrial enterprise, the following conclusions can be drawn:

1. Indicators to assess the efficiency of the innovative path of development of an enterprise are formed, which together reflect the level of efficiency of using the results of scientific and technological progress.

2. The main factors that affect the efficiency of innovative development of an enterprise and characterize the outstripping growth of production on the basis of scientific and technological progress are identified.

3. A functional relationship has been established between the performance indicators of the introduction of innovations and the factors acting on it, which allows for given (planned) factors to find the corresponding estimates of performance indicators.

4. For the analysis and assessment of the efficiency of innovative development of an enterprise, the optimal combination of factors for its increase is proposed, based on the fact that many factors affecting the efficiency of economic activity, together with the complexity of their relationships, have optimal ranges of actions.

\section{Reference}

1. L. Vodachek, O. Vodachkova, Enterprise innovation management strategy (Economics, Moscow, 2004) 
2. Yu. Yakovets, Innovation: theory, mechanism, state regulation (RAGS, Moscow, 2008)

3. S. Ilyenkova, L. Gokhberg, S. Yagudin, Innovation management (UNITI, Moscow, 2007)

4. L. Ogoleva, Innovation management (INFRA, Moscow, 2005)

5. R. Fathutdinov, Innovation management (St. Petersburg, Piter, 2011)

6. J. Schumpeter, The Theory of Economic Development (Progress, Moscow, 1982).

7. G. Teeling-Smith, Science, Industry and the State (Pergamon, 1965)

8. Jan Verloop, Insight in Innovation (Elsevier Science, 2004)

9. Lars Frølund Max Riedel, Strategic Industry-University Partnerships (Academic Press, 2018)

10. C. Freeman, Output Measurement in Science and Technology (North Holland, 1987)

11. Charis Galanakis, Innovation Strategies in the Food Industry (Academic Press, 2016).

12. M. Garcia Martinez, Open Innovation in the Food and Beverage Industry (Woodhead Publishing 2013).

13. Peter Weegels, Consumer Driven Cereal Innovation (2009)

14. Craig Leadley, Innovation and Future Trends in Food Manufacturing and Supply Chain Technologies (Woodhead Publishing, 2015)

15. J.J. Lambin, Market-Driven Management: Strategic and Operational Marketing (St. Petersburg, Piter, 2004)

16. R. Tucker, Driving Growth Through Innovation: How Leading Firms Are Transforming Their Futures (Olympus Business, Moscow, 2006)

17. A. Butnik-Seversky, A. Sheremet, Y. Reilian, Economic and mathematical methods of analysis in the economic activity of enterprises and associations (Finance and Statistics, Moscow, 1982)

18. A. Magomedov, V. Melekhin., V. Musaeva, Herald of the Dagestan Scientific Center, $10(2001)$

19. A. Mottaeva, , E3S Web of Conferences, 110, 02164, (2019) doi.org/10.1051/e3sconf /201911002164

20. T.S. Meshcheryakova, MATEC Web of Conferences, 193, 01048 (2018) 